\title{
Lack of controlled studies investigating the risk of postpartum haemorrhage in cesarean delivery after prior use of oxytocin: a scoping review
}

Karin Bischoff ${ }^{1}$, Monika Nothacker $^{2}$, Cornelius Lehane ${ }^{3}$, Britta Lang ${ }^{1}$, Joerg Meerpohl ${ }^{1}$ and Christine Schmucker $^{1 *}$

\begin{abstract}
Background: Postpartum haemorrhage (PPH) is a major cause of maternal mortality and morbidity worldwide. Experimental and clinical studies indicate that prolonged oxytocin exposure in the first or second stage of labour may be associated with impaired uterine contractility and an increased risk of atonic PPH. Therefore, particularly labouring women requiring cesarean delivery constitute a subset of patients that may exhibit an unpredictable response to oxytocin. We mapped the evidence for comparative studies investigating the hypothesis whether the risk for PPH is increased in women requiring cesarean section after induction or augmentation of labour.
\end{abstract}

Methods: We performed a systematic literature search for clinical trials in Medline, Embase, Web of Science, and the Cochrane Library (May 2016). Additionally we searched for ongoing or unpublished trials in clinicaltrials.gov and the WHO registry platform. We identified a total of 36 controlled trials investigating the exogenous use of oxytocin in cesarean section. Data were extracted for study key characteristics and the current literature literature was described narratively.

Results: Our evidence map shows that the majority of studies investigating the outcome PPH focused on prophylactic oxytocin use compared to other uterotonic agents in the third stage of labour. Only 2 dose-response studies investigated the required oxytocin dose to prevent uterine atony after cesarean delivery for labour arrest. These studies support the hypotheses that labouring women exposed to exogenous oxytocin require a higher oxytocin dose after delivery than non-labouring women to prevent uterine atony after cesarean section. However, the study findings are flawed by limitations of the study design as well as the outcome selection. No clinical trial was identified that directly compared exogenous oxytocin versus no oxytocin application before intrapartum cesarean delivery.

Conclusion: Despite some evidence from dose-response studies that the use of oxytocin may increase the risk for $\mathrm{PPH}$ in intrapartum cesarean delivery, current research has not investigated the prepartal application of oxytocin in well controlled clinical trials. It was striking that most studies on exogenous oxytocin are focused on PPH prophylaxis in the third stage of labour without differing between the indications of cesarean section and hence the prepartal oxytocin status.

Keywords: Oxytocin, Uterotonics, Postpartum haemorrhage, Intrapartum cesarean section

\footnotetext{
*Correspondence: schmucker@cochrane.de

${ }^{1}$ Cochrane Germany, Medical Center - University of Freiburg, Faculty of

Medicine, University of Freiburg, Freiburg, Germany

Full list of author information is available at the end of the article
} 


\section{Background}

Postpartum haemorrhage (PPH) is a major cause of maternal mortality and morbidity worldwide [1-4]. Approximately $36 \%$ of all lower segment cesarean deliveries and between 6 and 14\% of spontaneous deliveries are complicated by $\mathrm{PPH}$, depending on the definition used and the population studied [5-7]. Although global mortality from PPH is falling, its incidence is increasing in several high resource settings $[8,9]$. In the United States, between 1994 and 2006, the rate of atonic PPH increased by $160 \%$ among women undergoing cesarean section after induction of labour and 130\% among women undergoing non-induced cesarean section [10]. This increase may be explained by the increasing rates of cesarean sections and associated complications caused by general anesthesia, operative techniques or complications such as placental abruption leading to an emergency cesarean section $[8,11-14]$, but also due to an extensive use of uterotonics to induce or augment labour [7, 14].

The most widely used uterotonic drug for augmenting labour or to maintain uterine contractility during labour is oxytocin $[15,16]$. Oxytocin, which was first synthetically synthesized in 1953 is also the first choice in the prevention and treatment of uterine atony [17]. When given in low-dose, oxytocin induces rhythmic uterine contractions which are indistinguishable in frequency, duration and strength from contractions observed during spontaneous labour $[18,19]$. On the other hand, oxytocin for inducing or augmenting labour may desensitise the oxytocin receptors, thereby impairing oxytocin's post-delivery effects on uterine contractility [18]. For example, Balki et al. showed in different in vitro studies that pretreatment with oxytocin decreases oxytocin-induced myometrial contractions in pregnant humans and animals [20-22]. In addition, Grotegut et al. conducted a retrospective study on women who experienced severe $\mathrm{PPH}$ and found that these women received significantly greater amounts of oxytocin during labour compared with women without $\mathrm{PPH}$, suggesting that prolonged pre- or intrapartum exposure to oxytocin might lead to decreased drug efficacy [23]. Similarly, Belghiti et al. investigated in a population-based case-control study the association between the level of oxytocin exposure during labour and the risk of severe atonic PPH [24, 25]. The study showed that oxytocin exposure during labour appears to be an independent risk factor for severe PPH in woman with spontaneous labour who did not receive prophylactic oxytocin after delivery (odds ratio after adjustment for all potential confounders [adjusted OR]: $1.8,95 \%$ CI 1.3 to 2.6$)$. Thereby, the strength of the association increased with the amount of oxytocin infused during labour [24, 25].
Considering that $\mathrm{PPH}$ rates are higher in cesarean section compared to spontaneous labour [7], particularly labouring women requiring cesarean delivery may constitute a subset of patients that may exhibit a negative response to exogenous oxytocin [14-16]. Therefore, we mapped the current literature for controlled clinical studies investigating the risk of atonic $\mathrm{PPH}$ in labouring women requiring cesarean delivery (intrapartum cesarean section) after oxytocin use for labour induction or augmentation in comparison to no exogenous oxytocin.

\section{Methods \\ Sources}

We adhered to the Preferred Reporting Items for Systematic reviews and Meta-Analyses (PRISMA) protocol for identifying, screening and eligibility of studies to conduct the present research work [see Additional file 1].

We searched for controlled clinical studies investigating exogenous oxytocin in cesarean delivery, irrespective of delivery indication, age, comorbidity or woman's parity. Primary maternal outcomes, we were interested in, included PPH rates, adverse effects or the need for additional uterotonics. In addition we collated any neonatal outcomes reported. A review protocol can be accessed from the corresponding author (CS).

Published studies were identified from searches of electronic databases. We searched Medline (OvidSP), Embase, Web of Science, the Cochrane library from inception until May 2016. The search strategy was based on combinations of medical subject headings (MeSH) and keywords and was not restricted to specific languages. The search strategy used in Medline (OvidSP) is presented in an additional file [see Additional file 2]. Search strategies for other databases were modified to meet the requirements of each database. The searches were supplemented by screening the bibliographies of relevant studies and systematic reviews. Potential ongoing studies were identified in the International Clinical Trials Registry Platform WHO (http://www.who.int/ ictrp/en/) and the Register for Clinical Trials (http:// clinicaltrials.gov/).

\section{Study selection}

One author (KB) screened the titles and abstracts of all reports identified by electronic searches. We obtained full-text copies of all potentially relevant articles and 2 reviewers $(\mathrm{KB}, \mathrm{CS})$ assessed them for inclusion. These authors also independently carried out data extraction for key characteristics of the study, participant and intervention.

\section{Data analysis (mapping the evidence)}

First, study characteristics such as country, study design, details of the intervention and control intervention, time 
point of drug application, week of gestation, sample size, age and indication for cesarean section were extracted and tabulated. Second, we looked whether the given $\mathrm{PPH}$ rates were stratified after the indication for cesarean delivery and/or when only women with intrapartum cesarean section were included whether the results were stratified after the use of oxytocin versus no oxytocin before surgery. By considering key characteristics of all studies investigating oxytocin in cesarean section, evidence gaps for a subset of women could be identified and a narrative description of the current literature provided.

\section{Results}

\section{Published studies}

We identified 7866 titles and abstracts; for 432 of these, the full text was evaluated. Figure 1 outlines the screening and selection process of the articles. Table 1 presents the key characteristics of the 36 controlled trials investigating the risk of PPH after the use of exogenous oxytocin in cesarean section: 23 randomized controlled trials (RCTs) (including 4084 patients), 2 comparative dose- response studies (including 100 patients) and 11 nonRCTs (including 3896 patients).

\section{Intrapartum cesarean delivery}

From 36 studies identified, 8 studies (1705 patients) included solely women requiring intrapartum cesarean delivery, mainly because of labour arrest [26-33]. However, from these 8 studies, only 2 dose-response studies addressed the hypothesis whether parturients who receive intrapartum exogenous ocytocin are prone to a higher risk of PPH by evaluating uterine contraction after delivery [26, 27]: (i) Thereby, the dose-response study from Lavoie et al. investigated whether women who receive intrapartum exogenous oxytocin, and who subsequently undergo cesarean delivery for labour dystocia, need a higher estimated effective dose of oxytocin in $90 \%$ of women (ED90) compared with non-labouring parturients [27]. Thirty-two women participated in the labouring and 38 women in the non-labouring group. The reported oxytocin ED90 was significantly greater for the labouring group requiring cesarean delivery compared with that for the non-labouring group (mean difference:

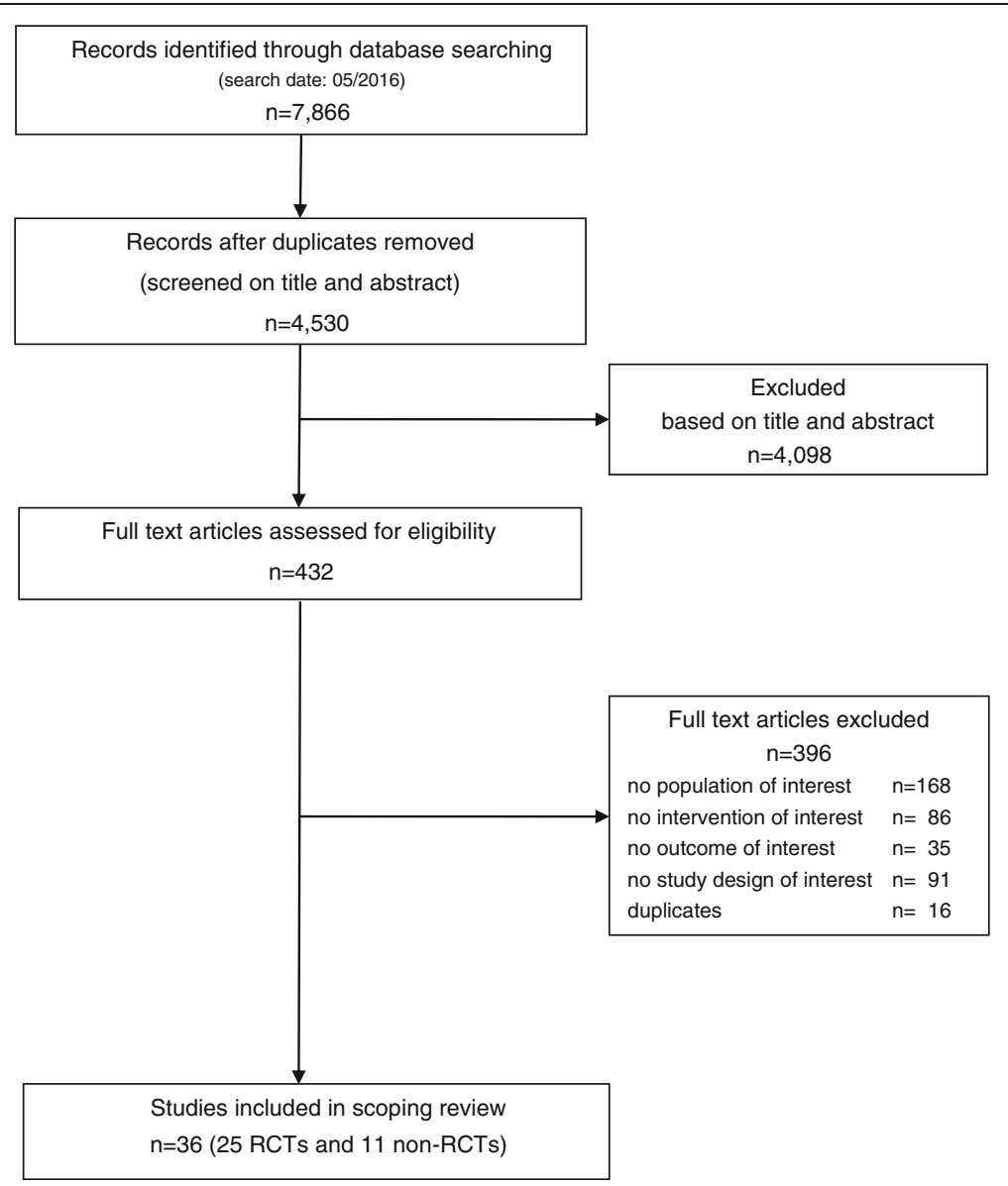

Fig. 1 PRISMA flow diagram: Results of the bibliographic literature search in Medline, Embase, Web of Science, and the Cochrane Library in May 2016 (as published by Moher D et al. in BMJ 2009;339:62535). RCT: randomized controlled trial 


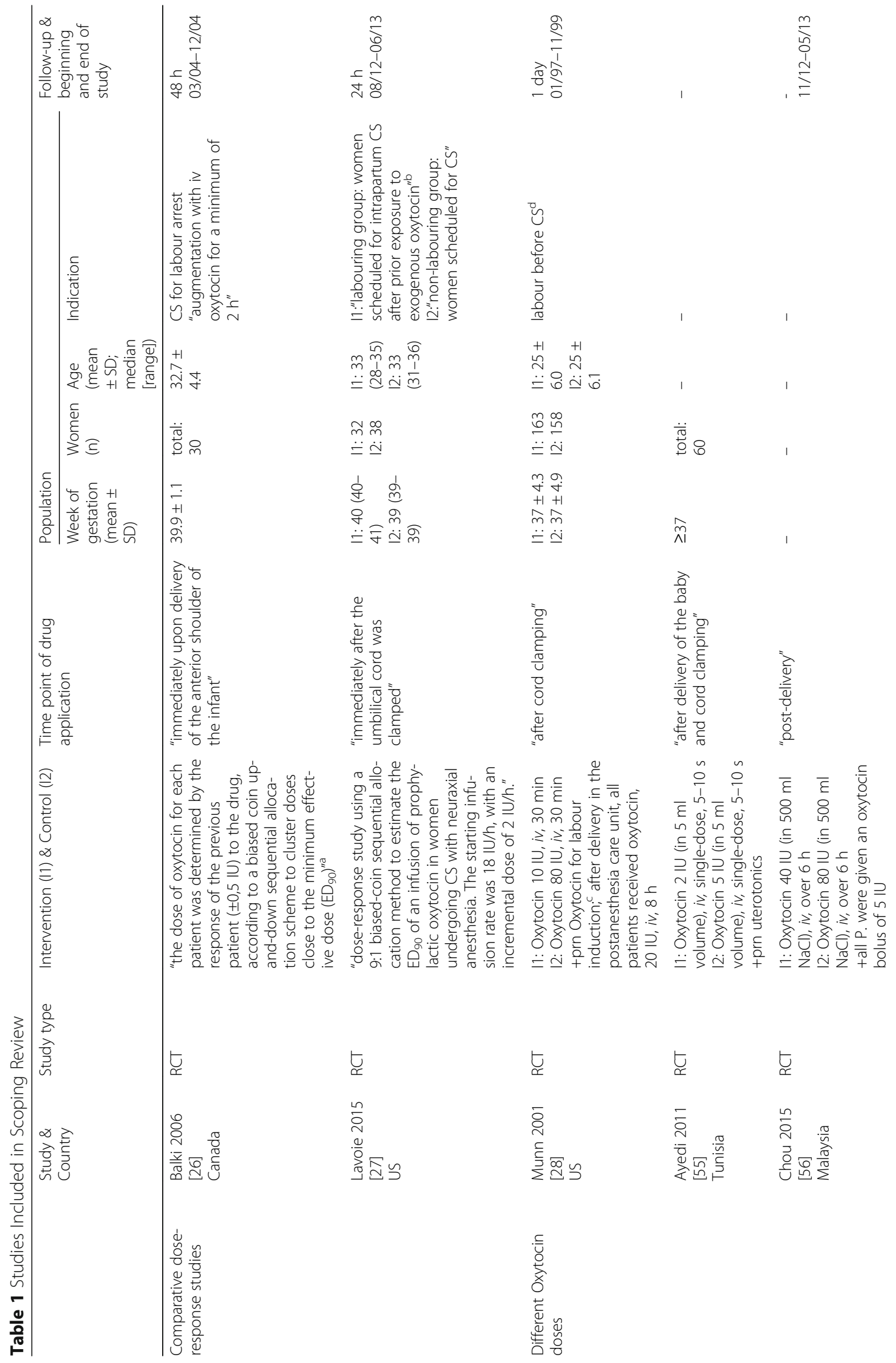









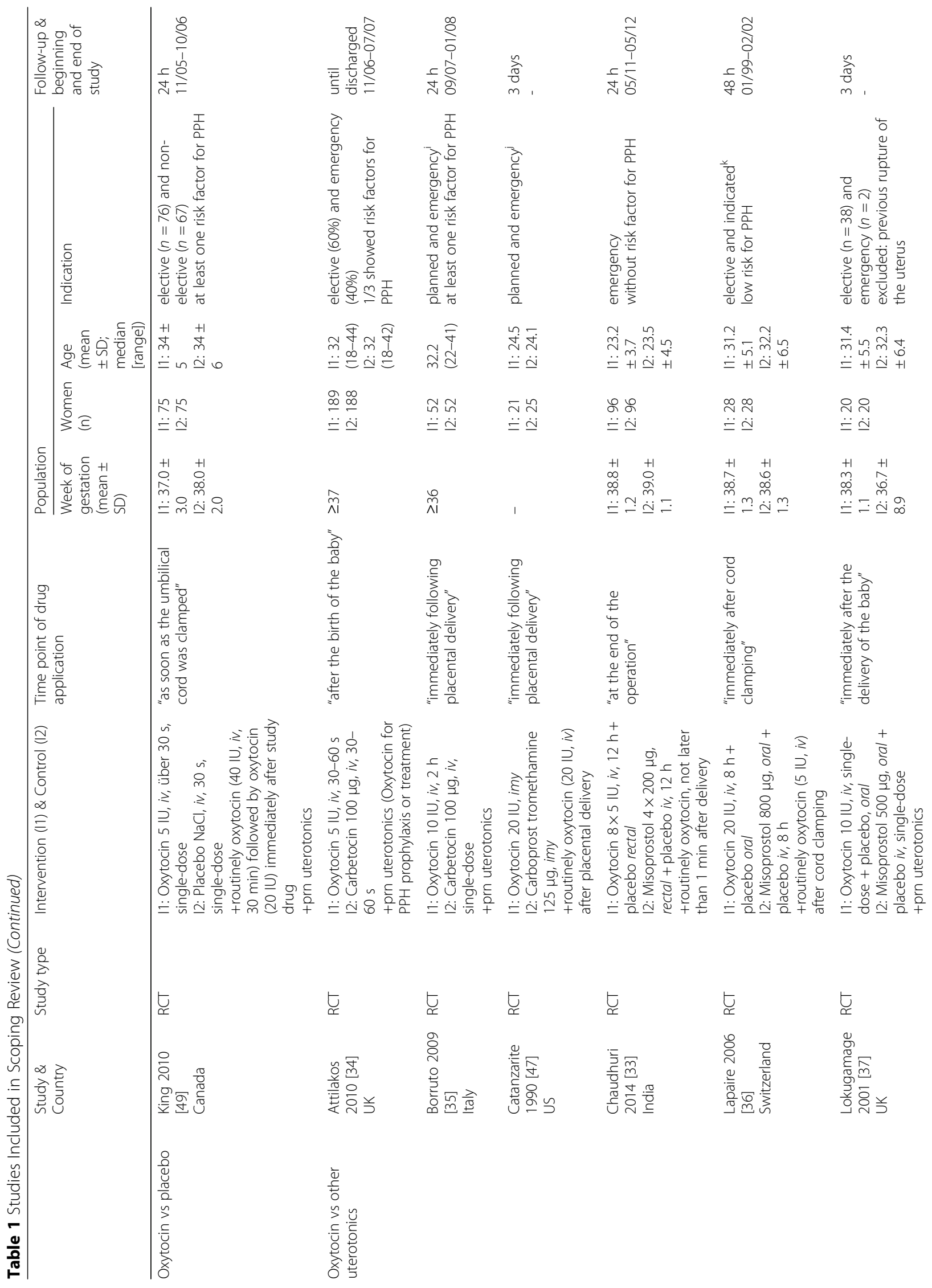




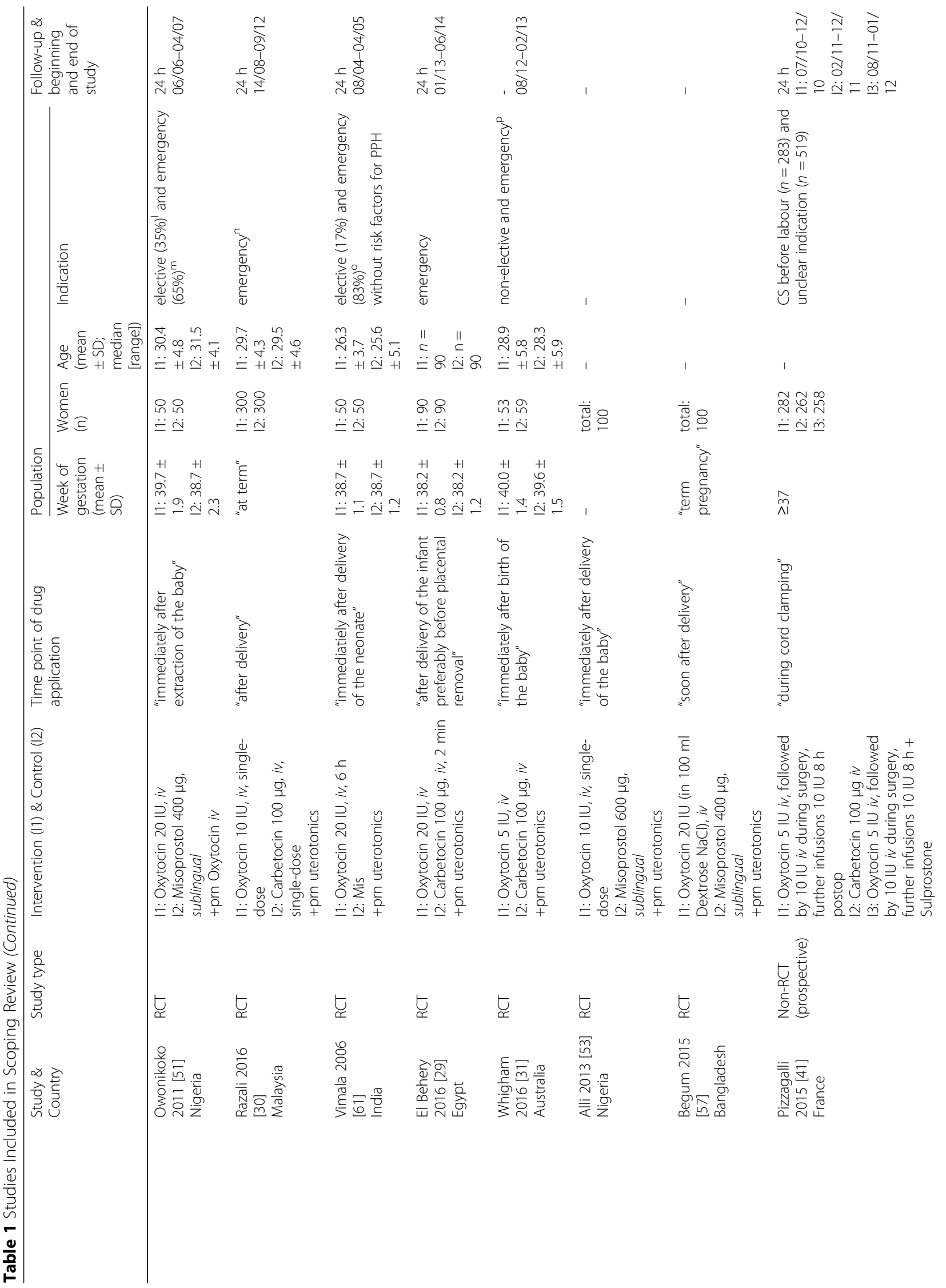




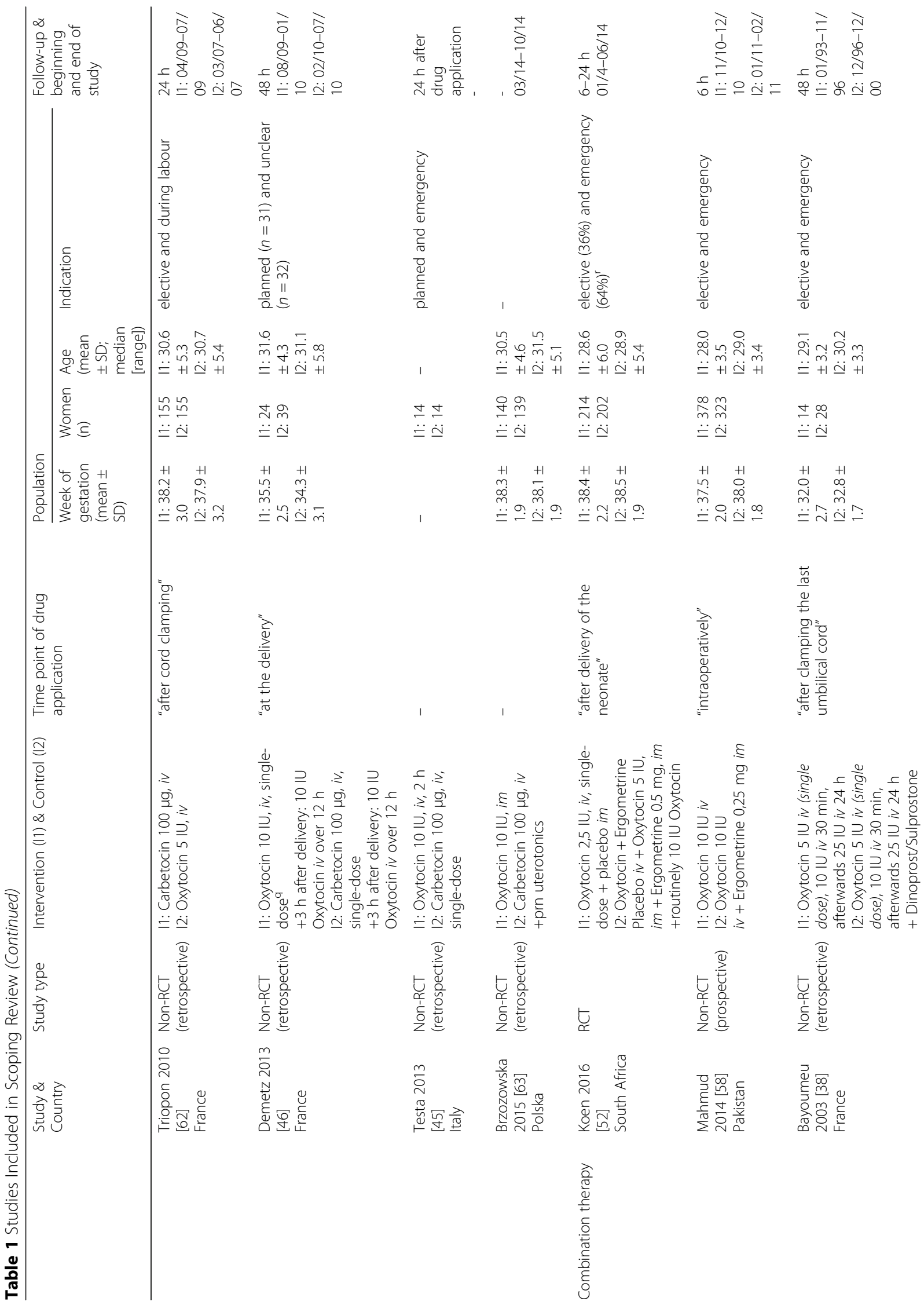




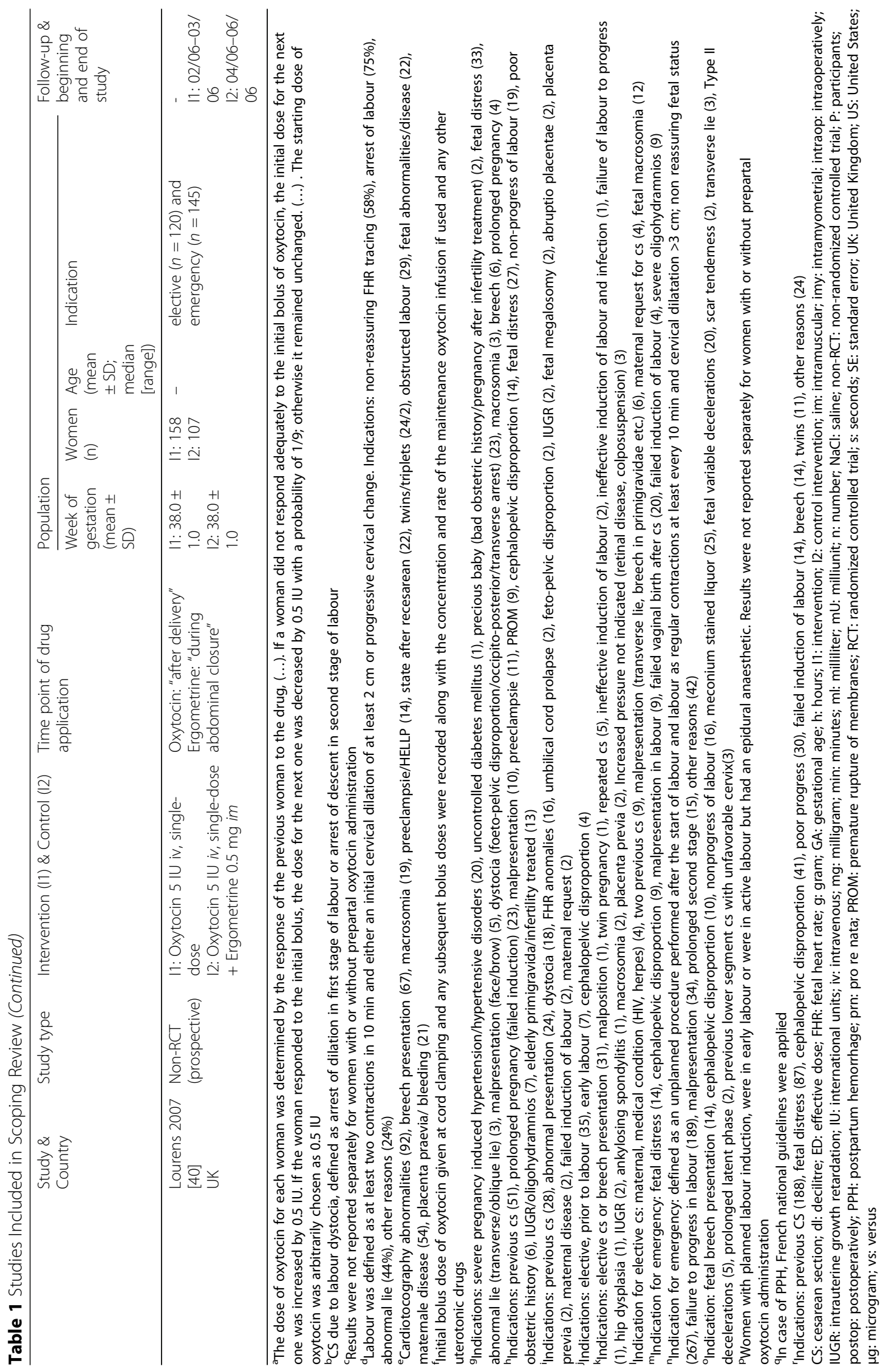


28 Units/h [95\% CI 26-29 Units/h, $P<0.001])$. Furthermore, significantly more women in the labouring group compared to the non-labouring group required additional uterotonic agents (mean difference: 26\% [95\% CI $7-44 \%, P=0.008]$ ). (ii) The other dose-response study from Balki et al. estimated the minimum effective intravenous dose of oxytocin required for adequate uterine contraction after cesarean delivery for labour arrest, however, without using an active control group [26]. In this study, all 30 patients received oxytocin infusion at a mean of $9.8 \pm 6.3 \mathrm{~h}$ before cesarean delivery. After delivery, oxytocin was administered as a slow intravenous bolus according to a coin up-down sequential allocation scheme. The minimum oxytocin ED90 required to produce adequate uterine response was estimated to be $3.0 \mathrm{U}$ (95\% CI 2.3-3.7 U). The authors concluded that women with intrapartum cesarean section for labour arrest require an oxytocin dose that is 9 times higher than previously reported after elective cesarean section in non-labouring women at term. However, the results of these dose-response studies are limited by comparing different patient populations without controlling for potential confounders such as women with increased risk of uterine atony, age, anticoagulant medication, general anaesthesia or multiple pregnancy. In addition, the authors used 'satisfactory uterine contraction' assessed by palpating the uterus as main outcome. Beside the fact that this outcome is subjective and not validated to estimate the effect of oxytocin on the uterus, it can not be excluded that due to a lack of blinding of the obstetricians, different thresholds for satisfactory uterine tone in women with prior labour compared with non-labouring women were used. Therefore, theses study results need to be interpreted with caution. The remaining 6 studies including women with intrapartum cesarean sections investigated different doses or application schedules of exogenous oxytocin or compared oxytocin to other uteronotics after cesarean delivery for $\mathrm{PPH}$ prophylaxis [28-32]. Whether the prepartal oxytocin status is a risk factor for atonic PPH could not be derived from these studies.

\section{Intrapartum and prelabour cesarean delivery}

Our mapping also revealed that the majority of studies investigating $\mathrm{PPH}$ rates for different treatment groups are focused on prophylactic uterogenics and included women with different types of cesarean delivery (intrapartum and prelabour cesarean section). However, the $\mathrm{PPH}$ rates given in these studies were not stratified according to the indications for cesarean section. In addition, the prepartal oxytocin status was not considered as confounding factor by conducting subgroup analyses [34-63].

\section{Ongoing studies}

The search for ongoing and unpublished studies identified 2 RCTs which may provide subgroup data estimating the blood loss and risk for $\mathrm{PPH}$ after cesarean section for labour arrest (ClinicalTrials.gov Identifier: NCT01869556 and NCT02794779). The estimated completion date for both studies is by the end of 2017. In addition, we identified HOLDS, a multicentre, doubleblind randomised controlled trial to compare standard and high dose regimens of oxytocin for women with confirmed delay in the first stage of labour (http:// www.isrctn.com/ISRCTN99841044). This trial randomises 1500 women and measure differences in rates and complications associated with cesarean section. If this study provides a subgroup analysis of PPH rates in those women requiring cesarean sections, important insights addressing the present research question will be given.

\section{Discussion}

Current clinical practice guidelines for third stage oxytocin administration do not distinguish between women with prior oxytocin exposure and those without $[64,65]$. This practice is also reflected by the current research in cesarean delivery, which showed that the majority of studies investigating oxytocin focus on prophylactic administration in the third stage of labour, without differing between the indications for cesarean section and, hence the prepartal oxytocin status (particularly when labour was induced or augmented). However, taking into account that labouring women requiring cesarean delivery constitute a relevant subset of patients - for whom originally spontaneous labour was anticipated - the lack of studies solely investigating this patient population is not surprising.

In total, our evidence map revealed that only 2 studies investigated the required oxytocin dose to prevent uterine atony after cesarean delivery for labour arrest. These dose-response studies support the hypothesis that labouring women exposed to exogenous oxytocin require a higher oxytocin dose after delivery than nonlabouring women to prevent uterine atony after cesarean section. This finding is in accordance with the observations during spontaneous labour [24, 25]. However, the studies investigating this hypothesis in intrapartum cesarean delivery are all flawed by limitations of the study design as well as the outcome selection. Thus, the estimated oxytocin ED90 may be lower in labouring women than actually reported.

A limitation of our research work is that data could not be formally synthesized due to a lack of controlled studies evaluating the impact of ante partum oxytocin use on the risk of PPH in exogenous cesarean delivery. Nevertheless, the current scoping review describes key data of published studies investigating the routine use of 
oxytocin in caesarean delivery in their quantity, but also reveals major research gaps in this important but underrepresented obstetric area. It is obvious that research on this topic is mainly restricted to augmentation or induction of vaginal delivery $[16,66,67]$ or the prophylactic use in the third stage of labour to prevent PPH $[15,68]$. But such data would have been only relevant to address our research question, if they had allowed us to derive $\mathrm{PPH}$ rates for those women who required intrapartum cesarean delivery (e.g., data from subgroup analyses). A Cochrane Review from 2013 investigated oxytocin augmentation of labour in women with epidural analgesia for reducing operative deliveries [69]. This review provides rates for cesarean sections after oxytocin exposure in comparison to placebo, but whether there is a difference in $\mathrm{PPH}$ rates for women requiring cesarean section were also not provided. Taking into account that the current research does not provide us with rigorous controlled data to address our research question, access to individual and/or unpublished study data may be desirable [70]. Although overall progress has been made to obtain such study data, there are still major issues related to unrestricted data access. For example, released data may be incomplete, selective or not in compliance with the results reported in the corresponding publications. Facing these issues, we did not undertake efforts to include such data in our research work.

We believe that the current scoping review is important because it reveals that published research on oxytocin is restricted to the use for inducing or augmenting labour or for $\mathrm{PPH}$ prophylaxis, without considering women requiring intrapartum cesarean section - not even in subgroup analyses. Given the increasing rates in cesarean sections and labour inductions in many developed countries [71], well controlled studies are needed focusing on these parturient. Taking into account that different studies suggest that induction of labour increases the risk of postpartum hemorrhage and blood transfusion $[24,71]$, caution is needed when intrapartum cesarean section is performed, particularly when labour is induced or augmented, as it may result in increased maternal morbidity.

\section{Conclusions}

Considering that research on the risk of PPH after oxytocin exposure is generally restricted to the use of $\mathrm{PPH}$ prophylaxis and vaginal births, future controlled studies should evaluate whether administration of oxytocin in cesarean delivery is associated with a higher risk of PPH taking into account that labouring and non-labouring women may show a difference response to exogenous oxytocin. In addition, these studies should control for known confounding factors associated with a higher risk of $\mathrm{PPH}$ such as multiple pregnancy, assisted reproductive technologies, general anaesthesia, type of uterine incision or advanced maternal age $[6,13,14,72]$. As long as there is no evidence-based guideline available for labouring women requiring cesarean delivery, obstetricans and anaesthesiologists should always be aware of an increased risk of PPH due to prior oxytocin exposure in this patient population.

\section{Additional files}

Additional file 1: PRISMA (2009) Checklist. (DOC $60 \mathrm{~kb}$ )

Additional file 2: Search Strategy in Medline (OvidSP). (DOCX 14 kb)

\section{Abbreviations}

Cl: Confidence Interval; ED: Effective Dose; IU: International Unit; OR: Odds Ratio; PPH: Postpartum Haemorrhage; PRISMA: Prefered Reporting Items for Systematic Reviews and Meta-Analyses; RCT: Randomized Controlled Trial; WHO: World Health Organization

\section{Acknowledgements}

This project was initiated by the German Society for Gynecology and Obstetrics to answer a clinical question for the multidisciplinary expert group of the German evidence- and consensus-based guideline project "Sectio Cesarea" (AWMF-Registry number 015-084, coordinator: Prof. Dr. med. F. Louwen). The authors also thank Edith Motschall from the University of Freiburg for conducting the comprehensive systematic literature search and Katharina Kunzweiler (Cochrane Germany) for conducting the search for ongoing studies in the study registries.

\section{Funding}

This project was funded by the German Federal Ministry of Health, \#GE20160425. The funders had no role in the conduct or reporting of the scoping review.

\section{Availability of data and materials}

All data presented in this scoping review were identified through database searches outlined in the methods section.

\section{Authors' contributions}

$\mathrm{CS}$ and $\mathrm{MN}$ are responsible for the coordination, conception and design of the review. KB reviewed titles and abstracts. Screening of full-texts and data extraction were undertaken by CS and KB. CS wrote a first draft and $J M, C L$, $\mathrm{MN}$ and $\mathrm{BL}$ revised the manuscript critically for important intellectual content. All authors have read and approved the final version of the publication.

Ethics approval and consent to participate

Not applicable - scoping review.

Consent for publication

Not applicable - scoping review.

Competing interests

The authors declare that they have no competing interests.

\section{Publisher's Note}

Springer Nature remains neutral with regard to jurisdictional claims in published maps and institutional affiliations.

\section{Author details}

${ }^{1}$ Cochrane Germany, Medical Center - University of Freiburg, Faculty of Medicine, University of Freiburg, Freiburg, Germany. ${ }^{2}$ AWMF-Institute for Medical Knowledge Management (IMWi), Karl-von-Frisch-Street 1, 35043 Marburg, Germany. 'Department of Anesthesiology and Critical Care, University Heart Center Freiburg-Bad Krozingen, Medical Center - University of Freiburg, Freiburg, Germany. 
Received: 4 August 2017 Accepted: 20 November 2017 Published online: 29 November 2017

\section{References}

1. Khan KS, Wojdyla D, Say L, Gulmezoglu AM, Van Look PF. Who analysis of causes of maternal death: a systematic review. Lancet. 2006; 367(9516):1066-74.

2. Zwart JJ, Richters JM, Ory F, de Vries JI, Bloemenkamp KW, van Roosmalen J. Severe maternal morbidity during pregnancy, delivery and puerperium in the netherlands: a nationwide population-based study of 371,000 pregnancies. BJOG. 2008;115(7):842-50,

3. Baskett TF, O'Connell CM. Severe obstetric maternal morbidity: a 15-year population-based study. J Obstet Gynaecol Can. 2005:25(1):7-9.

4. Magann EF, Evans S, Hutchinson M, Collins R, Howard BC, Morrison JC. Postpartum hemorrhage after vaginal birth: an analysis of risk factors. South Med J. 2005;98(4):419-22

5. Gizzo S, Patrelli TS, Gangi SD, Carrozzini M, Saccardi C, Zambon A, Bertocco A, Fagherazzi S, D'Antona D, Nardelli GB. Which uterotonic is better to prevent the postpartum hemorrhage? Latest news in terms of clinical efficacy, side effects, and contraindications: a systematic review. Reprod Sci. 2013;20(9):1011-9.

6. Weeks AD, Neilson JP. Rethinking our approach to postpartum haemorrhage and uterotonics. BMJ. 2015;351:h3251.

7. Bateman BT, Berman MF, Riley LE, Leffert LR. The epidemiology of postpartum hemorrhage in a large, nationwide sample of deliveries. Anesth Analg. 2010;110(5):1368-73.

8. Knight M, Callaghan WM, Berg C, Alexander S, Bouvier-Colle MH, Ford JB, Joseph KS, Lewis G, Liston RM, Roberts $\mathrm{CL}$, et al. Trends in postpartum hemorrhage in high resource countries: a review and recommendations from the international postpartum hemorrhage collaborative group. BMC Pregnancy Childbirth. 2009;9:55

9. Menard MK, Main EK, Currigan SM. Executive summary of the revitalize initiative: standardizing obstetric data definitions. Obstet Gynecol. 2014; 124(1):150-3.

10. Callaghan WM, Mackay AP, Berg CJ. Identification of severe maternal morbidity during delivery hospitalizations, united states, 1991-2003. Am J Obstet Gynecol. 2008;199(2):133.e1-8.

11. Briley A, Seed PT, Tydeman G, Ballard H, Waterstone M, Sandall J, Poston L, Tribe RM, Bewley S. Reporting errors, incidence and risk factors for postpartum haemorrhage and progression to severe pph: a prospective observational study. BJOG. 2014;121(7):876-88.

12. Mathai M, Hofmeyr GJ. Abdominal surgical incisions for caesarean section. Cochrane Database Syst Rev. 2007;(1):Cd004453.

13. Butwick AJ, Ramachandran B, Hegde P, Riley ET, El-Sayed YY, Nelson LM. Risk factors for severe postpartum hemorrhage after cesarean delivery: casecontrol studies. Anesth Analg. 2017:125(2):523-32.

14. Combs CA, Murphy EL, Laros RK, Jr. Factors associated with hemorrhage in cesarean deliveries. Obstet Gynecol 1991;77(1):77-82.

15. Westhoff G, Cotter AM, Tolosa JE. Prophylactic oxytocin for the third stage of labour to prevent postpartum haemorrhage. Cochrane Database Syst Rev. 2013;10:CD001808

16. Bugg GJ, Siddiqui F, Thornton JG. Oxytocin versus no treatment or delayed treatment for slow progress in the first stage of spontaneous labour. Cochrane Database Syst Rev. 2013;6:CD007123.

17. Arthur P, Taggart MJ, Mitchell BF. Oxytocin and parturition: a role for increased myometrial calcium and calcium sensitization? Front Biosci. 2007: 12:619-33.

18. Phaneuf S, Rodriguez Linares B, TambyRaja RL, MacKenzie IZ, Lopez Bernal A. Loss of myometrial oxytocin receptors during oxytocin-induced and oxytocin-augmented labour. J Reprod Fertil. 2000;120(1):91-7.

19. Fraser W, Vendittelli F, Krauss I, Breart G. Effects of early augmentation of labour with amniotomy and oxytocin in nulliparous women: a metaanalysis. BJOG. 1998;105(2):189-94.

20. Balki M, Erik-Soussi M, Kingdom J, Carvalho JC. Oxytocin pretreatment attenuates oxytocin-induced contractions in human myometrium in vitro. Anesthesiology. 2013;119(3):552-61

21. Balki M, Cristian AL, Kingdom J, Carvalho JC. Oxytocin pretreatment of pregnant rat myometrium reduces the efficacy of oxytocin but not of ergonovine maleate or prostaglandin f 2 alpha. Reprod Sci. 2010;17(3): 269-77.
22. Magalhaes JK, Carvalho JC, Parkes RK, Kingdom J, Li Y, Balki M. Oxytocin pretreatment decreases oxytocin-induced myometrial contractions in pregnant rats in a concentration-dependent but not time-dependent manner. Reprod Sci. 2009;16(5):501-8.

23. Grotegut CA, Paglia MJ, Johnson LN, Thames B, James AH. Oxytocin exposure during labor among women with postpartum hemorrhage secondary to uterine atony. Am J Obstet Gynecol. 2011;204(1):56.e1-6.

24. Belghiti J, Kayem G, Dupont C, Rudigoz RC, Bouvier-Colle MH, DeneuxTharaux C. Oxytocin during labour and risk of severe postpartum haemorrhage: a population-based, cohort-nested case-control study. BMJ Open. 2011;1(2):e000514.

25. Belghiti J, Coulm B, Kayem G, Blondel B, Deneux-Tharaux C. Oxytocin administration during labor. Results from the 2010 french national perinatal survey. J Gynecol Obstet Biol Reprod. 2013;42(7):662-70.

26. Balki M, Ronayne M, Davies S, Fallah S, Kingdom J, Windrim R, Carvalho JCA. Minimum oxytocin dose requirement after cesarean delivery for labor arrest. Obstet Gynecol. 2006;107(1):45-50.

27. Lavoie A, McCarthy RJ, Wong CA. The ed90 of prophylactic oxytocin infusion after delivery of the placenta during cesarean delivery in laboring compared with nonlaboring women: an up-down sequential allocation dose-response study. Anesth Analg. 2015:121(1):159-64.

28. Munn MB, Owen J, Vincent R, Wakefield M, Chestnut DH, Hauth JC. Comparison of two oxytocin regimens to prevent uterine atony at cesarean delivery: a randomized controlled trial. Obstet Gynecol. 2001;98(3):386-90.

29. El Behery MM, El Sayed GA, Abd El Hameed AA, Soliman BS, Abdelsalam WA, Bahaa A. Carbetocin versus oxytocin for prevention of postpartum hemorrhage in obese nulliparous women undergoing emergency cesarean delivery. J Matern-Fetal Neonatal Med. 2016;29(8):1257-60.

30. Razali N, Latar ILM, Chan YK, Omar SZ, Tan PC. Carbetocin compared to oxytocin in emergency cesarean section: a randomized trial. Eur J Obstet Gynecol Reprod Biol. 2016;198:35-9.

31. Whigham CA, Gorelik A, Loughnan TE, Trivedi A. Carbetocin versus oxytocin to reduce additional uterotonic use at non-elective caesarean section: a double-blind, randomised trial. J Matern Fetal Neonatal Med. 2016:1-4.

32. Khan MS, Sinha SK, Sultana T, Singhal S. Comparison of two oxytocin infusions in patients undergoing emergency cesarean sections: a double blind study. Int J Gynecol Obstet. 2012;119:S389.

33. Chaudhuri P, Mandi S, Mazumdar A. Rectally administrated misoprostol as an alternative to intravenous oxytocin infusion for preventing postpartum hemorrhage after cesarean delivery. J Obstet Gynaecol Res. 2014:40(9):2023-30.

34. Attilakos G, Psaroudakis D, Ash J, Buchanan R, Winter C, Donald F, Hunt LP, Draycott T. Carbetocin versus oxytocin for the prevention of postpartum haemorrhage following caesarean section: the results of a double-blind randomised trial. BJOG. 2010;117(8):929-36.

35. Borruto F, Treisser A, Comparetto C. Utilization of carbetocin for prevention of postpartum hemorrhage after cesarean section: a randomized clinical trial. Arch Gynecol Obstet. 2009;280(5):707-12

36. Lapaire O, Schneider MC, Stotz M, Surbek DV, Holzgreve W, Hoesli IM. Oral misoprostol vs. intravenous oxytocin in reducing blood loss after emergency cesarean delivery. Int J Gynecol Obstet. 2006:95(1):2-7.

37. Lokugamage AU, Paine M, Bassaw-Balroop K, Sullivan KR, El Refaey H, Rodeck $\mathrm{CH}$. Active management of the third stage at caesarean section: a randomised controlled trial of misoprostol versus syntocinon. Aust N Z J Obstet Gynaecol. 2001:41(4):411-4.

38. Bayoumeu F, Baka NE, Fresson J, Monnier-Barbarino P. Do prophylactic prostaglandins reduce the transfusion rate at cesarean section in high-order multiple pregnancies? Eur J Obstet Gynecol Reprod Biol 2003;111(1):38-42.

39. Brzozowska M, Lisiecki D, Kowalska-Koprek U, Karowicz-Bilinska A. Comparison of carbetocin and oxytocin effectiveness for prevention of postpartum hemorrhage after caesarean delivery. Ginekol Polska. 2015; 86(2):107-12.

40. Lourens R, Paterson-Brown S. Ergometrine given during caesarean section and incidence of delayed postpartum haemorrhage due to uterine atony. J Obstet Gynaecol. 2007;27(8):795-7.

41. Pizzagalli F, Agasse J, Marpeau L. Comparison between carbetocin and oxytocin during cesarean section in the prevention of postpartum haemorrhage. Gynecol Obstet Fertil. 2015:43(5):356-60.

42. Pursche T, Diedrich K, Banz-Jansen C. Blood loss after caesarean section: depending on the management of oxytocin application? Arch Gynecol Obstet. 2012;286(3):633-6. 
43. Triopon G, Goron A, Agenor J, Aya GA, Chaillou AL, Begler-Fonnier J, Bousquet PJ, Mares P. Use of carbetocin in prevention of uterine atony during cesarean section. Comparison with oxytocin. Gynecol Obstet Fertil. 2010;38(12):729-34.

44. McClune G, Laird R. Oxytocin doses for caesarean section: a standardised approach. Anaesthesia. 2011;66:20.

45. Testa S, Paoletti O, Dellanoce C, Bassi L, Stramezzi M, Spotti E, Mammoliti D, Riccardi A. Carbetocin increase thrombin generation after cesarean section. JTH. 2013;11(Suppl. 2):738.

46. Demetz J, Clouqueur E, D'Haveloose A, Staelen P, Ducloy AS, Subtil D. Systematic use of carbetocin during cesarean delivery of multiple pregnancies: a before-and-after study. Arch Gynecol Obstet. 2013;287(5): 875-80.

47. Catanzarite VA. Prophylactic intramyometrial carboprost tromethamine does not substantially reduce blood-loss relative to intramyometrial oxytocin at routine cesarean-section. Am J Perinatol. 1990;7(1):39-42.

48. Lee Al, Wong CA, Healy L, Toledo P. Impact of a third stage of labor oxytocin protocol on cesarean delivery outcomes. Int J Obstet Anesth. 2014; 23(1):18-22.

49. King KJ, Douglas MJ, Unger W, Wong A, King RAR. Five unit bolus oxytocin at cesarean delivery in women at risk of atony: a randomized, double-blind, controlled trial. Anesth Analg. 2010;111(6):1460-6.

50. Adefuye PO, Akindele RA, Adefuye BO, Durojaiye BO, Adeiyi TO. Effect of pre-operative sub-lingual misoprostol versus intravenous oxytocin on caesarean operation blood loss. East Afr Med J. 2012;89(9):294-300.

51. Owonikoko KM, Arowojolu AO, Okunlola MA. Effect of sublingual misoprostol versus intravenous oxytocin on reducing blood loss at cesarean section in nigeria: a randomized controlled trial. J Obstet Gynaecol Res. 2011;37(7):715-21.

52. Koen S, Snyman LC, Pattinson RC, Makin JA. A randomised controlled trial comparing oxytocin and oxytocin + ergometrine for prevention of postpartum haemorrhage at caesarean section. SAMJ. 2016;106(4):399-402.

53. Alli QO. Comparing effectiveness of sublingual misoprostol with oxytocin infusion to reduce blood loss at caesarean section: double blind, randomised study. BJOG. 2013;120:77-8.

54. Kintu A, Nakubulwa S, Mijumbi C, Kwizera A, Tindimwebwa J. Uterotonic efficacy of oxytocin 2.5 versus 10 units during caesarean section at mulago hospital: a double blinded placebo controlled randomised clinical trial. $\mathrm{Br}$ J Anaesth. 2012;108:197-8

55. Ayedi M, Zouche I, Smaoui L, Bouaziz I, Smaoui M, Kolsi K. Comparison of 2 versus 5 units of oxytocin in caesarean section. Eur J Anaesthesiol. 2011;28: 159-60.

56. Chou LT, Da AL, Murizah MZ, Rushdan MMN, Rashid ZMRA. Randomised controlled trial on low dose versus high dose oxytocin infusion in prevention of uterine atony at caesarean delivery. J Obstet Gynaecol Res. 2015;41:44-5.

57. Begum T, Yeasmin S, Chakma S. Sublingual misoprostol versus oxitocin infusion to reduce blood loss in caesarean section. BJOG. 2015;122:258.

58. Mahmud G, Javaid K, Tasnim N, Tabassum A, Bangash KT. Where does ergometrine stand in prevention of postpartum haemorrhage in caesarean section? J Pak Med Assoc. 2014;64(8):911-4.

59. Mangla D, Goel JK, Goel R. Prophylactic intramyometrial oxytocin before placenta delivery during cesarean section prevents postpartum hemorrhage: a prospective randomized study of 150 women. J SAFOG. 2012:4(2):93-6.

60. Chaudhuri P, Banerjee GB, Mandal A. Rectally administered misoprostol versus intravenous oxytocin infusion during cesarean delivery to reduce intraoperative and postoperative blood loss. Int J Gynecol Obstet. 2010; 109(1):25-9.

61. Vimala N, Mittal S, Kumar S. Sublingual misoprostol versus oxytocin infusion to reduce blood loss at cesarean section. Int J Gynecol Obstet. 2006;92(2): $106-10$

62. Triopon G, Goron A, Agenor J, Aya GA, Chaillou AL, Begler-Fonnier J, Bousquet PJ, Mares P. Use of carbetocin in prevention of uterine atony during cesarean section. Gynecol Obstet Fertil. 2010;38(12):729-34

63. Brzozowska M, Lisiecki D, Kowalska-Koprek U, Karowicz-Bilinska A. Comparison of carbetocin and oxytocin effectiveness for prevention of postpartum hemorrhage after caesarean delivery. Ginekol Pol. 2015;86(2):107-12.

64. Acog ACOG. Practice bulletin: clinical management guidelines for obstetrician-gynecologists number 76, october 2006: postpartum hemorrhage. Obstet Gynecol. 2006;108(4):1039-47.
65. Leduc D, Senikas V, Lalonde AB, Ballerman C, Biringer A, Delaney M, Duperron L, Girard I, Jones D, Lee LS, et al. Active management of the third stage of labour: prevention and treatment of postpartum hemorrhage. J Obstet Gynaecol Can. 2009;31(10):980-93.

66. Budden A, Chen L, Henry A. High-dose versus low-dose oxytocin infusion regimens for induction of labour at term. Cochrane Database Syst Rev. 2014;10:CD009701.

67. Kenyon S, Tokumasu H, Dowswell T, Pledge D, Mori R. High-dose versus low-dose oxytocin for augmentation of delayed labour. Cochrane Database Syst Rev. 2013;7:CD007201

68. Oladapo OT, Okusanya BO, Abalos E. Intramuscular versus intravenous prophylactic oxytocin for the third stage of labour. Cochrane Database Syst Rev. 2012;2:CD009332.

69. Costley PL, East CE. Oxytocin augmentation of labour in women with epidural analgesia for reducing operative deliveries. Cochrane Database Syst Rev. 2013;7:CD009241.

70. Schmucker CM, Blumle A, Schell LK, Schwarzer G, Oeller P, Cabrera L, von Elm E, Briel M, Meerpohl JJ. Systematic review finds that study data not published in full text articles have unclear impact on meta-analyses results in medical research. PLoS One. 2017:12(4):e0176210.

71. Grobman WA. Elective induction: when? Ever? Clin Obstet Gynecol. 2007; 50(2):537-46.

72. Nyflot LT, Sandven I, Stray-Pedersen B, Pettersen S, Al-Zirqi I, Rosenberg M Jacobsen AF, Vangen S. Risk factors for severe postpartum hemorrhage: a case-control study. BMC Pregnancy Childbirth. 2017;17(1):17.

\section{Submit your next manuscript to BioMed Central and we will help you at every step:}

- We accept pre-submission inquiries

- Our selector tool helps you to find the most relevant journal

- We provide round the clock customer support

- Convenient online submission

- Thorough peer review

- Inclusion in PubMed and all major indexing services

- Maximum visibility for your research

Submit your manuscript at www.biomedcentral.com/submit 